136

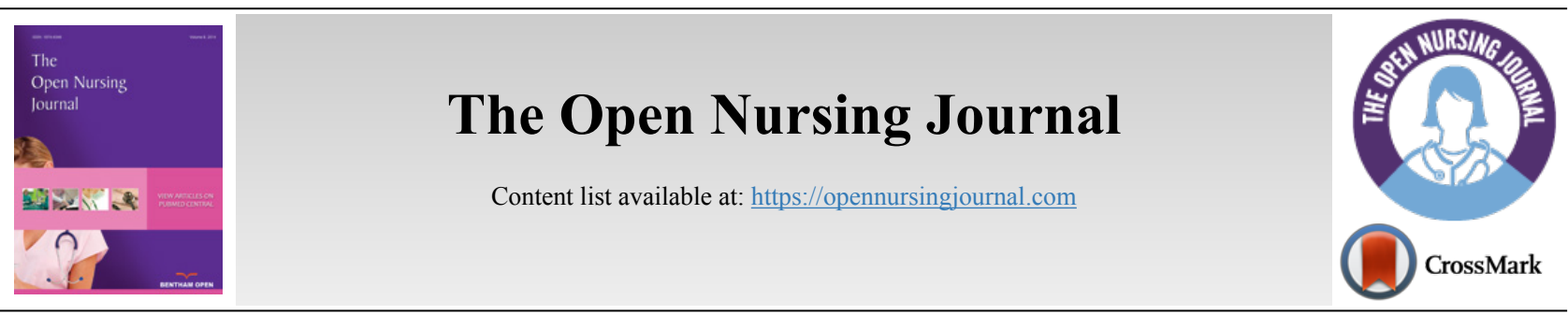

RESEARCH ARTICLE

\title{
A Qualitative Description of Nurses' Psychological Responses in Caring for COVID-19 Patients: An Indonesian Context
}

Suhartini Ismail ${ }^{1, *}$, Muhamad Ridlo ${ }^{1}$ and Nana Rochana ${ }^{1}$

${ }^{1}$ Department of Nursing, Emergency and Critical Care Division, Universitas Diponegoro, Tembalang, Semarang, Central Java, Indonesia

\begin{abstract}
:
Introduction:

COVID-19 is a dangerous, infectious disease that has affected the whole world in the past year. In Indonesia, many nurses were not only infected by the virus but also experienced varying psychological responses in providing treatment and performing their tasks. In other words, they faced the daunting responsibility of fighting the disease while taking care of COVID-19 patients.

Objective:

The study aimed to describe nurses' psychological responses in caring for COVID-19 patients in Indonesia.

Methods:

This was a qualitative descriptive study involving 13 nurses. Using purposive sampling, the participants were selected from three public hospitals in Semarang, Indonesia. These nurses were assigned to take care of COVID-19 patients in the isolation room. The participants underwent face-toface interviews, either by video calls or through an online application, using semi-structured and in-depth guidelines. The collected data were analyzed using Ello and Kyngas inductive content analysis.

Results:

During the pandemic, the nurses had the following psychological responses in caring for COVID-19 patients in Indonesia: 1) being constantly stressed in carrying out their duties; 2) having no choice but happy to help patients recover at the same time, and 3) getting closer to God as a form of spiritual relief.

Conclusion:

This study provides fundamental data related to further psychological interventions for nurses who experience psychological problems during the COVID-19 pandemic.
\end{abstract}

Keywords: Caring, COVID-19 patients, Nurses, Psychological responses, Stress, Qualitative description.

\begin{tabular}{|l|l|l|l|}
\hline Article History & Received: March 20, 2021 & Revised: July 1, 2021 & Accepted: July 15, 2021 \\
\hline
\end{tabular}

\section{INTRODUCTION}

COVID-19 is a viral infection that has caused a continued increase in the number of confirmed cases worldwide since its outbreak in Wuhan and the rest of Hubei Province. Since then, COVID-19 has threatened the health of human beings throughout the world [1]. COVID-19 is a highly contagious viral infection caused by Severe Acute Respiratory Syndrome-

\footnotetext{
* Address correspondence to this author at the Department of Nursing, Emergency and Critical Care Division, Universitas Diponegoro, Tembalang, Semarang, Central Java, Indonesia;

Tel: +62 81288439996; Fax: +6224 76486849;

E-mail: suhartini.ismail@fk.undip.ac.id
}

Coronavirus 2 (SARS-CoV-2). It first appeared in Wuhan, China, and spread throughout the world. SARS-CoV-2 is phylogenetically related to bat animals; therefore, bats can be a potential primary reservoir [2]. As agents, humans have contributed to the quick spread of COVID-19 [3]. Indeed, the ongoing human transmission has resulted in COVID-19 being a global pandemic that has continued to affect human health and lifestyles [4].

The COVID-19 pandemic is a public health crisis that has posed a significant challenge to healthcare providers. WHO has taken active and effective steps to provide health services and help control the spread of COVID-19 [5]. Health workers 
implement their duties to combat the disease, and among these, nurses are considered the leading force in treating COVID-19 patients [2]. Unfortunately, these nurses also suffer from physical and psychological health problems related to the treatment of patients [6].

As healthcare providers, nurses are also involved in the diagnosis, treatment, and care of COVID-19 patients, including preventing and responding to COVID-19 transmission [7, 8]. However, the depletion of self-protective equipment, lack of certain drugs, and feelings that are not sufficiently supported have created a psychological burden in their provision of services [9].

For one, the nurses may feel a sense of loneliness and confusion associated with working in COVID-19 isolation facilities. They face a situation in which they come into actual contact with the disease but receive insufficient security from disappointment, segregation, seclusion, patients with negative feelings, and the absence of contact with their relatives [10]. Moreover, in the isolation room situation, the patient is also alone and undertreated, and feelings of uncertainty [11]. Thus, in isolation facilities, both the patients and their nurses experience isolation.

Evidence has shown that nurses are afraid of passing COVID-19 infection to their families, friends, and peers [12]. Moreover, some of them experience stress, anxiety, anger, denial and may even develop depressive symptoms [9, 13]. They have feelings of uncertainty and experience heavy stigmatization associated with the infection [14, 15]. Nurses also experience sleeping difficulties [9]. Some of the psychological problems that occur include disturbed attention, understanding, and ability to make health workers' decisions, which may hinder the struggle against COVID-19 [10]. It means that nurses' psychological responses resulting from the COVID-19 pandemic vary depending on the exposure levels. The exposure levels of COVID-19 may differ according to the countries and cultures. Some studies had reported mental states of the health workers who care for COVID-19 patients in China and Pakistan $[7-10,16]$. However, only a little evidence to date revealed the psychological responses, particularly of nurses in Indonesia in caring for COVID-19 patients. The proposed research question is what the nurse's psychological responses in caring for COVID-19 patients are. Hence, the aim of this study is to describe nurses' psychological responses in caring for COVID-19 patients in Indonesia.

\section{METHODS}

\subsection{Study Design}

This research used a qualitative descriptive study approach. A qualitative descriptive study is a scientific research technique that is used to provide an overview of new and in-depth knowledge about certain events or phenomena. As mentioned previously, this study focused on the psychological responses of nurses in caring for COVID-19 patients. A qualitative description design is particularly appropriate to use if the information is obtained directly from those experiencing the phenomenon being investigated and in situations wherein time and resources are limited [17].
Qualitative description also seeks to describe an experience in an easily understood language [18]. Therefore, a qualitative description approach offers the opportunity to gather detailed descriptions of phenomena about which little has been known so far. The focus on producing a detailed description of the phenomenon from those who have the experience offers a unique opportunity to gain emic knowledge and learn about how the respondents see their world [17].

\subsection{Setting and Participants}

Nurses from three public hospitals were encouraged to participate in this study. The participants were selected using a purposive sampling method. To enrich the data, 13 nurses joined this study and were willing to share their experience intime. The inclusion criteria were as follows: 1) nurses who were taking care of COVID-19 patients, 2) male and female nurses aged 20-30 years, and 3) professional nurses with two or more years of work experience. The participants were informed about the study and the procedures to be performed and were asked to sign a written consent form before commencing the study. In this situation, the informed consent forms were signed electronically using an online platform.

\subsection{Ethical Consideration}

The Health Research Ethics Committee of the Department of Nursing, Universitas Diponegoro, approved the research with number 128/EC/KEPK/D.Kep/IX2020. The guidelines of ethical research during the COVID-19 pandemic came from the WHO (2020) guidelines available on its website. Before conducting the research, researchers obtained the informed consent via Google Forms. Each form contained information about the research objectives and methods used in the study. Once the participants had read all the information on the given form, they were asked to select the "Agree" option in the space provided to confirm their consent to this research. The researchers assured the participants of confidentiality of all the information obtained.

\subsection{Data Collection}

Data were collected using in-depth online interviews conducted on June 2020. The researchers communicated the study's objectives, dealt with participants in advance, and scheduled the interview times. The researchers then conducted face-to-face interviews via video calls. During the interview by telephone and video call, the researchers recorded all conversations made. Each interview lasted for 20-30 minutes per participant. The interview rounds were conducted three times based on the appointments scheduled. The study participants were allowed to withdraw their consent anytime during the research process. Nevertheless, the researchers aimed to establish a good relationship with the participants.

In gathering data, three steps were conducted. The first step was the pre-interview, which involved (1) creating a trustworthy situation between the researchers and participants, (2) giving information to the participants regarding informed consent, and (3) setting appointments to interview the participants by video call based on each participant's free time. The second step involved the interview phase as follows: (1) 
giving a definite time of 20-30 minutes to talk via video call, (2) recording the interviews, (3) giving questions based on the interview guidelines, (4) listening to the 20 - to 30 -minute interviews, 5) encouraging the participants to answer all the questions, and 6) focusing on and clarifying whether a topic was not relevant to the information given by the participants. The third step post-interview involved the researchers asking for a continued interview in the future to clarify some information.

The research questions were as follows:

1) What are your perceptions of being a nurse in the front line in terms of caring for COVID-19 patients?

2) What are the psychological responses that you experience while caring for COVID-19 patients?

3) What impacts did you experience while caring for COVID-19 patients?

4) How do you protect yourself while caring for patients during the COVID-19 pandemic?

5) What are your expectations during the COVID-19 pandemic?.

Data on the general information were analyzed and entered as discrete data on a table. Codes represented by P1-P13 served as each participant's pseudonym, respectively. The information was gathered and investigated via qualitative content analysis, thus allowing for a better and more flexible explanation of the data in a meaningful way [17].

Data analysis followed Ello and Kyngas method using inductive content analysis. The analysis processes were, preparation, organizing, and reporting [18]. The preparation process was preparing the raw verbatim data. Organizing the concepts was derived from the data in inductive content analysis. Finally, reporting included describing generated themes as the findings of the study. Inductive content analysis moreover is used when a qualitative study has an inductive starting point or, when the data collection approach is open and follows loosely defined themes. This form of content analysis is suitable when the phenomenon under study has not been covered in previous studies or when prior knowledge is fragmented [18]. Since, the context of the study is pandemic bound that has not occurred before; a basic inductive content analysis was performed according to the following phases: data reduction, data grouping and the formation of concepts that can be used to answer research questions. The analysis data then concluded three main themes.

The researchers ensured trustworthiness during data analysis. The recorded data were transcribed verbally into text by the researchers. The interview responses were captured in Bahasa and then translated into English during the transcription process. The texts were refined by the entire research team, whose members were proficient in both languages. The retranslated texts were compared with the original record for equivalence and then for participant validation to increase credibility and ensure that the transcripts represented the meaning they were trying to convey during the interview. The researchers read the texts thoroughly and intuitively stressed their meanings (Table 1). A thick description ensured all the data were relayed verbatim and directly obtained from the participants. Confirmability checking was conducted to assess the readable meaning from the participants, whereas triangulation of concepts was carried out by consulting a qualitative study expert.

\section{Table 1. Example of data analysis}

\begin{tabular}{|c|c|c|}
\hline Participant Statement & Coding & Theme \\
\hline $\begin{array}{c}\text { There is a feeling of stress, because } \\
\text { we (nurses) should do self-isolation } \\
\text { after taking care of the patients with } \\
\text { COVID-19. I am stressed because I } \\
\text { have to work under much pressure; } \\
\text { then, we have to stay in the isolation } \\
\text { room for some hours during the shift, } \\
\text { and we (nurses) are not allowed to eat } \\
\text { or drink during the time. (P1) }\end{array}$ & $\begin{array}{c}\text { Stress } \\
\text { most common } \\
\text { feelings } \\
\text { experienced by } \\
\text { nurses. }\end{array}$ \\
\hline $\begin{array}{c}\text { As a nurse, I am happy to be able to } \\
\text { help or care for them (the patients). I } \\
\text { am proud of myself for delivering } \\
\text { patient recovery. (P6) }\end{array}$ & $\begin{array}{c}\text { Happy } \\
\text { Help } \\
\text { other }\end{array}$ & $\begin{array}{c}\text { They have no } \\
\text { choice, but are } \\
\text { happy to help the } \\
\text { patients and hope } \\
\text { for their recovery. }\end{array}$ \\
\hline
\end{tabular}

\section{RESULTS}

\subsection{Characteristics of Participants}

Information about the participants is presented in Table $\mathbf{2}$. The participants were nurses who were assigned to isolation rooms when the pandemic started. During the data gathering period, most of them have already been in duty in the isolation unit for a period of eight months, during which they have been taking care of around 50-100 COVID-19 patients.

Table 2. Participants' characteristics $(\mathrm{N}=13)$.

\begin{tabular}{|c|c|c|c|c|}
\hline Code & Age (year) & Sex & $\begin{array}{c}\text { Average of Duty } \\
\text { in an Isolation } \\
\text { Room (Months) }\end{array}$ & Number of Patients \\
\hline P1 & 38 & Male & 8 & $<50$ \\
\hline P2 & 33 & Female & 8 & $50-100$ \\
\hline P3 & 39 & Male & 7 & $<50$ \\
\hline P4 & 30 & Male & 8 & $50-100$ \\
\hline P5 & 31 & Female & 3 & $50-100$ \\
\hline P6 & 42 & Female & 8 & $50-100$ \\
\hline P7 & 34 & Female & 8 & $<50$ \\
\hline P8 & 33 & Female & 5 & $<50$ \\
\hline P9 & 33 & Male & 7 & $50-100$ \\
\hline P10 & 36 & Female & 4 & $<50$ \\
\hline P11 & 32 & Female & 6 & $<50$ \\
\hline P12 & 30 & Male & 8 & $<50$ \\
\hline P13 & 30 & Male & 8 & $<50$ \\
\hline
\end{tabular}

3.2. Themes Regarding the Nurses' Psychological Responses

The data revealed three main themes regarding the nurses' psychological responses: 1) being constantly stressed in carrying out their duties; 2) having no choice, but being happy to help patients recover at the same time; and 3) getting closer to God as a form of spiritual relief. 


\subsubsection{Being Constantly Stressed in Carrying out their Duties}

Throughout the pandemic, nurses experienced stress as they could not go back home and lacked time to communicate with family members. The participants also reported that they experienced much pressure, such as wearing constricting Personal Protective Equipment (PPE) and having extended work hours. There was also the problem of a lack of selfprotection equipment while treating their patients.

There is a feeling of stress because we (nurses) should do self-isolation after taking care of the patients with COVID-19. I am stressed, because I have to work under much pressure; then, we also have to stay in the isolation room for some hours during the shift, and we (nurses) are not allowed to eat or drink during the time. (P1)

The lack of personal protective equipment during the first wave of the COVID-19 pandemic made me feel mixed emotions about the situation. (P2)

So scary, I might bring the virus back home and infected my relatives. It makes me stress. (P3)

This pandemic is coming suddenly. We (nurses) do not have prior knowledge about the COVID-19. The evidence is also lack. Therefore, what we treat to the patients just only based on their signs and symptoms. (P4)

We (nurses) had much stress in carrying out the duties in the isolation room. We could not eat and drink as long as we were wearing the PPE. There is only a short time to relax and breathe. Many nurses experience fatigue, and finally they also get infected. (P7)

For me, I feel really stressed out and somehow fear and anxious because this disease is dangerous and have no medication to treat the patients who were confirmed with COVID-19. (P13)

\subsubsection{Having no Choice, but Happy to Help the Patients and Hope for their Recovery}

Nurses require support in carrying out their duties, and such support may come from family or the people closest to them who understand their duties as front-liner against COVID-19. The participants reported that they felt happy, because health workers were entrusted to take care of patients and/or prevent COVID-19. Thus, although they have no choice, they get to experience happiness while doing their job. The participants also hoped that the patients could recover immediately so that they could contact their family members and perform their everyday activities when they got well.

When I should go to the hospital as my shift hours, my family is the supporter for me and I realize if I cannot go back home at the same time. (P2)

During COVID-19 treatment, my only expectation is to have my patients get back to their healthy lives and gather with their respective families at home. (P5)

As a nurse, I am happy to be able to help or care for them (the patients). I am proud of myself for delivering patient recovery. (P6)
Just happy. I also do not have experience before. I let myself be happy with all situations that should be handled as a nurse. (P8)

I like singing, so I sing a song when I observe the patients insecure. I try myself to be happy and hope that the patients are happy too. (P10)

As a nurse, I am happy to be able to help or care for them. I am proud of myself for being entrusted with the healing of our patients. (P12)

Don't forget to be happy, as a happy feeling will increase the immunity. I hope the pandemic is over some time. (P13)

\subsubsection{Getting closer to God as a form of Spiritual Relief}

As long as they were in the frontline, the nurses demonstrated strong resilience in the fight against COVID-19. They reported gaining strength from praying or getting closer to God. They do believe that while caring for COVID-19 patients, they were always protected by God. The nurses confirmed that getting closer to God created a balance in life while taking care of the patients.

Getting closer to Godcan balance my life while taking care the patients, and overcome the crisis situation. This is my spiritual aspect as I feel safe when submitting to God's will. (P1)

Again, God will help us since He gives this pandemic situation for human in the world for a reason. As spiritual human beings, I, you, everyone should pray, pray, and pray to dismiss the virus. (P3)

God (Allah) will protect me when I am taking care of the patients... "Bismillah" (in the name of Allah). I ask God to grant me. (P5)

After I follow the health protocol restricted, I pray to God to protect me from the disease. Lastly, there is no the best helper except our God. (P8)

I always pray to God when I provide care for the patients and I ask for my safety and their wellness. (P10)

I always pray for strength, enthusiasm, and protection from God as the one true helper. Whenever I pray, I feel that my soul is energized to help the patients and that my immunity is increased. (P13)

\section{DISCUSSION}

The objective of the study to describe nurses' psychological responses in caring for COVID-19 patients in Indonesia had been addressed. The nurses confirmed that they had psychological responses such as stress, fear, being happy to help the patients and expect their recovery, and spiritual strength from God. It is argued that the findings of the study showed the phenomena of the nurse's responses to the COVID-19 patients in an Indonesian context.

In this study, most of the nurses caring for COVID-19 patients experienced stress, especially because of the high risk of being infected with COVID-19. Other stressors include, extended work hours, a strict environment, and self-isolation after treating a COVID-19 patient to prevent transmission to 
other people, especially their families. This finding is in line with previous studies in China. The studies reported that negative emotions such as helplessness, and mental health problems $e . g$ stress, appear in the early stage of the pandemic $[8,10]$. During the situation, the most significant stressor for them is self-isolation after treating COVID-19 patients. Selfisolation leads to a lack of communication with family members. Moreover, various pressures from the work environment cause stress, such as difficulty resting, eating, and drinking while taking care of COVID-19 patients. Suppose the nurses make a mistake regarding further actions, then they will surely be infected. Another cause of the perceived stress is the lack of PPE, which triggers feelings of sadness and even frustration among the nurses caring for COVID-19 patients [10]. Inadequate protection from contamination, overwork, discrimination, self-isolation, and lack of contact with family all lead to work-related stress. Continuous stress experience of nurses could lead to psychological distress, which will eventually affect their work output and ability to deal with certain situations, and also increase their absenteeism [19].

The feelings of fear also occur among nurses, such as fear of transmitting the virus to family members or the community. Feelings of fear also increase in relation to public stigma or negative public opinion about incorrect virus-related information. This finding is similar to another study revealing that fear was felt by the health care providers from COVID-19 appointed hospitals, particularly of becoming contracted or contracting others [7]. The results showed that fear is related to the transmission of COVID-19 to friends or family and the stigmatization of the community against health workers [17]. Thus, to minimize excessive fear, nurses are required to undergo independent isolation to prevent the risk of transmission to family members and the surrounding environment. Research also showed that anxiety occurs due to a lack of knowledge and changes in the environment during a pandemic [8]. The environmental changes may be due to increased service hours, such as changes in service schedules and information development from the COVID-19 pandemic [19].

Moreover, nurses may also experience changes in the work schedule while providing services to patients. The nurses should provide nursing services during patient care process and may be required to give much more comprehensive nursing care in the process. Following the current research results, the nurses should be responsible for treating patients with coronavirus infection. They consider this an unavoidable part of their job and a responsibility that cannot be escaped [11]. It is evident that nurses have high-risk jobs and should get better protection for their health and well-being for their sake and that of their families.

As frontline healthcare providers, nurses experience stress in carrying out their duties. Nevertheless, they also have feelings of happiness because they can help heal patients during the treatment period. It is the nurse's responsibility to provide services for the patients' comfort and healing. Nurses also feel proud because patients entrust their recovery to them during the treatment period. Thus, in the care process, the patient follows all directions and care given by the nurse. The nurse's presence makes patients feel safe such that they become entirely confident in the nurse who is looking after them. From the results of previous studies, nurses reported feeling happy because of a patient's good faith, respect, and active cooperation [7, 8]. Additionally, nurses also received appreciation and gratitude given by patients who recovered from COVID-19 [20, 21]. Indeed, such evidence raises hope that nurses are willing to treat COVID-19 patients.

The nurses also expressed hope that their patients can have better health conditions and are able to gather again with family members. Patients can also have normal activities, as usual, and do not experience negative stigma from the surrounding environment. The nurses are expected to be able to overcome COVID-19 and stop its transmission. The results show that, in preventing COVID-19, strict infection control guidelines are required, and special equipment, such as suitable PPE, can be used to reduce cases of COVID-19 [22]. Previous research results have revealed the desired hope of official information from the authorities regarding COVID-19, finding the infection source, and developing a vaccine as soon as possible [23]. All of these targets should continue so that everyone can work together to fight COVID-19.

From a spiritual aspect, during the handling of COVID-19 patients, nurses continue to perform worship as usual according to their personal beliefs. They performed worship activities according to their religion. The nurses always prayed to God before, during, and after taking care of their patients. The nurses also wish to have a closer relationship with Allah. The nurses believed that they would be given strength, enthusiasm, and protection while carrying out their duties in the frontline. Therefore, one's religious belief can serve as a positive coping mechanism during crisis time [24]. This study added information that the nurses believe that God is responsible for helping protect them against the disease. As mainly Indonesian nurses are Muslim, the nurses furthermore shared that getting closer to God makes them happy and helps relieve their stress. This distinctive finding shows that Indonesian nurses rely on God as a spiritual coping mechanism when they deal with uncertain situations during COVID-19 pandemic. This argument is supported by a study pointing out that spirituality engagement is one of Indonesian nurse's coping strategies in facing difficult situations, such as death and grief [25]. Moreover, the spiritual coping creates the balance of life during the crisis situation to enhance the level of connectedness to God, social life, and the environment [26].

\section{STRENGTHS AND LIMITATIONS}

Descriptive qualitative research has been carried out in several studies in the nursing field. This current research was conducted in relation to a common phenomenon during the COVID-19 pandemic. The study focused on nurses' psychological responses to taking care of COVID-19 patients. In the data collection process, however, we could not conduct face-to-face interviews. Thus, this research may be affected by limited time and the inability to explore the nurses' psychological responses more deeply. Nevertheless, the findings described the nurses' current feelings while caring for COVID-19 patient. Thus, the study can provide fundamental 
data for further investigations on designing interventions to help nurses overcome stressful situations related to their job when pandemic outbreak.

\section{IMPLICATIONS FOR PRACTICE}

This study highlights the fact that nurses must also be monitored while taking care of COVID-19 patients. There should be hospital policies regarding strict protocols during a pandemic. Mental health readiness while providing healthcare is essential in providing successful hospital services in a pandemic, because psychological readiness supports physical readiness. Likewise, spiritual relief enhances the psychological impact among the nurses to take care of the COVID-19 patients.

\section{CONCLUSION}

During the COVID-19 pandemic, nurses have experienced psychological responses while treating COVID-19 patients. The findings indicate that the most experienced psychological response is stress. Factors associated with stress include excessive work hours, fear, and anxiety, among others. Nevertheless, the nurses reported that, while they have no choice but to do the job, they are also happy in helping their patients recover, thus showing their great resilience amidst the pandemic. The nurses also recognize the importance of being closer to God as they seek strong protection against COVID-19 for themselves.

\section{ETHICS APPROVAL AND CONSENT TO PARTI- CIPATE}

The Health Research Ethics Committee of the Department of Nursing, Universitas Diponegoro, approved the research with approval number 128/EC/KEPK/D.Kep/IX2020.

\section{HUMAN AND ANIMAL RIGHTS}

No animals were used in this research. All human research procedures followed were in accordance with the ethical standards of the committee responsible for human experimentation (institutional and national), and with the Helsinki Declaration of 1975, as revised in 2013.

\section{CONSENT FOR PUBLICATION}

Informed consent was obtained from all the participants.

\section{AVAILABILITY OF DATA AND MATERIALS}

Not applicable.

\section{FUNDING}

None.

\section{CONFLICT OF INTEREST}

The authors declare no conflict of interest, financial or otherwise.

\section{ACKNOWLEDGEMENTS}

Declared none.

\section{REFERENCES}

[1] Lau H, Khosrawipour V, Kocbach P P. Internationally lost COVID-19 cases. J Microbiol Immunol Infect 2020; 53(3): 454-8.

[http://dx.doi.org/10.1016/j.jmii.2020.03.013]

[2] Shereen MA, Khan S, Kazmi A, Bashir N, Siddique R. COVID-19 infection: Origin, transmission, and characteristics of human coronaviruses. J Adv Res 2020; 24: 91-8. [http://dx.doi.org/10.1016/j.jare.2020.03.005] [PMID: 32257431]

[3] Wang H, Feng J, Shao L, et al. Contingency management strategies of the Nursing Department in centralized rescue of patients with coronavirus disease 2019. Int J Nurs Sci 2020; 7(2): 139-42. [http://dx.doi.org/10.1016/j.ijnss.2020.04.001] [PMID: 32292636]

[4] Chow R. A citizen's thoughts about COVID-19. Lancet 2020; 395(10231)e65

[http://dx.doi.org/10.1016/S0140-6736(20)30692-9] [PMID: 32222158]

[5] Li Z, Ge J, Yang M, et al. Vicarious traumatization in the general public, members, and non-members of medical teams aiding in COVID-19 control. Brain Behav Immun 2020; 88: 916-9. [http://dx.doi.org/10.1016/j.bbi.2020.03.007] [PMID: 32169498]

[6] Fiorillo A, Gorwood P. The consequences of the COVID-19 pandemic on mental health and implications for clinical practice. Eur Psychiatry 2020; 63(1)e32

[http://dx.doi.org/10.1192/j.eurpsy.2020.35] [PMID: 32234102]

[7] Liu Q, Luo D, Haase JE, et al. The experiences of health-care providers during the COVID-19 crisis in China: A qualitative study. Lancet Glob Health 2020; 8(6): e790-8.

[http://dx.doi.org/10.1016/S2214-109X(20)30204-7] [PMID: 32573443]

[8] Sun N, Wei L, Shi S, et al. A qualitative study on the psychological experience of caregivers of COVID-19 patients. Am J Infect Control 2020; 48(6): 592-8.

[http://dx.doi.org/10.1016/j.ajic.2020.03.018] [PMID: 32334904]

[9] Lai J. Factors associated with mental health outcomes among health care workers exposed to coronavirus disease 2019. JAMA network open 2020; 3(3): e203976.

[http://dx.doi.org/10.1001/jamanetworkopen.2020.3976]

[10] Kang L, Li Y, Hu S, et al. The mental health of medical workers in Wuhan, China dealing with the 2019 novel coronavirus. Lancet Psychiatry 2020; 7(3)e14

[http://dx.doi.org/10.1016/S2215-0366(20)30047-X] [PMID: 32035030]

[11] Kim Y. Nurses' experiences of care for patients with Middle East respiratory syndrome-coronavirus in South Korea. Am J Infect Control 2018; 46(7): 781-7.

[http://dx.doi.org/10.1016/j.ajic.2018.01.012] [PMID: 29502886]

[12] Maunder R, Hunter J, Vincent L, et al. The immediate psychological and occupational impact of the 2003 SARS outbreak in a teaching hospital. CMAJ 2003; 168(10): 1245-51.

[PMID: 12743065]

[13] Chua SE, Cheung V, Cheung C, et al. Psychological effects of the SARS outbreak in Hong Kong on high-risk health care workers. Can J Psychiatry 2004; 49(6): 391-3.

[http://dx.doi.org/10.1177/070674370404900609] [PMID: 15283534]

[14] Bai Y, Lin CC, Lin CY, Chen JY, Chue CM, Chou P. Survey of stress reactions among health care workers involved with the SARS outbreak. Psychiatr Serv 2004; 55(9): 1055-7.

[http://dx.doi.org/10.1176/appi.ps.55.9.1055] [PMID: 15345768]

[15] Bradshaw C, Atkinson S, Doody O. Employing a qualitative description approach in health care research. Glob Qual Nurs Res 2017; 42333393617742282

[http://dx.doi.org/10.1177/2333393617742282] [PMID: 29204457]

[16] Sullivan-Bolyai S, Bova C, Harper D. Developing and refining interventions in persons with health disparities: the use of qualitative description. Nurs Outlook 2005; 53(3): 127-33.

[http://dx.doi.org/10.1016/j.outlook.2005.03.005] [PMID: 15988449]

[17] Rana W, Mukhtar S, Mukhtar S. Mental health of medical workers in Pakistan during the pandemic COVID-19 outbreak. Asian J Psychiatr 2020; 51102080

[http://dx.doi.org/10.1016/j.ajp.2020.102080] [PMID: 32283512]

[18] Elo S, Kyngäs H. The qualitative content analysis process. J Adv Nurs 2008; 62(1): 107-15.

[http://dx.doi.org/10.1111/j.1365-2648.2007.04569.x] [PMID: 18352969]

[19] Donovan RO, Doody O, Lyons R. The effect of stress on health and its implications for nursing. Br J Nurs 2013; 22(16): 969-970, 972-973. 
[http://dx.doi.org/10.12968/bjon.2013.22.16.969] [PMID: 24037402]

[20] Inter-Agency Standing Committee. Catatan tentang aspek kesehatan jiwa dan psikososial wabah COVID-19 versi 10 2020; 1-20. Available from:

https://www.who.int/docs/default-source/searo/indonesia/covid19/catat an-tentang-aspek-kesehatan-jiwa-dan-psikososial-wabah-covid-19feb-2020-indonesian.pdf?sfvrsn=ebae5645_2

[21] Mohindra R, R R, Suri V, Bhalla A, Singh SM. Issues relevant to mental health promotion in frontline health care providers managing quarantined/isolated COVID19 patients. Asian J Psychiatr 2020; 51(102084)102084

[http://dx.doi.org/10.1016/j.ajp.2020.102084] [PMID: 32289728]

[22] Cai H, Tu B, Ma J, et al. Psychological impact and coping strategies of frontline medical staff in Hunan between January and March 2020 during the outbreak of coronavirus disease 2019 (COVID-19) in Hubei, China. Med Sci Monit 2020; 26e924171
[http://dx.doi.org/10.12659/MSM.924171] [PMID: 32291383]

[23] Yin X, Zeng L. A study on the psychological needs of nurses caring for patients with coronavirus disease 2019 from the perspective of the existence, relatedness, and growth theory. Int J Nurs Sci 2020; 7(2): 157-60.

[http://dx.doi.org/10.1016/j.ijnss.2020.04.002] [PMID: 32292633]

[24] Goodman B. Faith in a time of crisis. American Psychological Association 2020. Available from: https://www.apa.org/topics/covid-19/faith-crisis

[25] Betriana F, Kongsuwan W. Grief reactions and coping strategies of muslim nurses dealing with death. Nurs Crit Care 2020; 25(5): 277-83. [http://dx.doi.org/10.1111/nicc.12481] [PMID: 31667986]

[26] Ismail S, Hatthakit U. Islam-based caring for the harmony of life among moslem critically Ill patients. Evidence Based Care 2018; 8(2): $28-38$

[http://dx.doi.org/10.22038/ebcj.2018.28213.167]

\section{(C) 2021 Ismail et al.}

This is an open access article distributed under the terms of the Creative Commons Attribution 4.0 International Public License (CC-BY 4.0), a copy of which is available at: https://creativecommons.org/licenses/by/4.0/legalcode. This license permits unrestricted use, distribution, and reproduction in any medium, provided the original author and source are credited. 